\title{
INDÚSTRIA CULTURAL E ESPORTE DEVEM SE INTERLIGAR PELA PUBLICIDADE.
}

\author{
José Maurício Capinussú ${ }^{1}$ \\ ${ }^{1}$ Universidade Salgado de Oliveira (UNIVERSO) - Rio de Janeiro - RJ - Brasil.
}

\begin{abstract}
Resumo: O presente trabalho objetiva estabelecer um elo entre esporte e indústria cultural, a partir do instante em que ambos norteiam seus procedimentos, dentro de uma visão moderna e realista, sem mascaramentos e hipocrisia, por princípios de comercialização e lucro, naturalmente obedecendo a princípios éticos e morais, sem apelar para expedientes que a sociedade critica condena. Tendo origem na década de 40 (1947) na Alemanha, a indústria cultural teve no berlinense Theodor Adorno o seu grande apologista, segundo ele, representando o estudo da comunicação sob o enfoque dos efeitos sociais de caráter ideológico dos meios de comunicação, efeitos esses que subordinam a ideologia ao princípio de comercialização da informação. A influência da indústria cultural, segundo opiniões de intelectuais que se aprofundaram no estudo do problema, pode ser prejudicial para o esporte, exigindo providências capazes de neutralizar este lado negativo, utilizando-se o recurso da publicidade como uma espécie de antídoto, cuja aplicação viria beneficiar o esporte.
\end{abstract}

Palavras-chave: Cultura, esporte, publicidade

Abstract: This study aims to establish a link between sport and culture industry, from the moment when both guide their procedures within a modern and realistic vision, without masking and hypocrisy, on the principles of marketing and profit, of course following ethical and moral principles, without appealing to resources that society condemns and criticizes. Originated in the 40s (1947) in Germany, the cultural industry had Berlin Theodor Adorno as its big fan, who said he represents the study of communication under the focus of the social character of ideological media, effects which ideology subordinated to the principle of marketing information. The influence of cultural industry, according to intellectuals' opinions that further studied the problem, can be detrimental to the sport, requiring measures capable of neutralizing the negative side, using the appeal of advertising as a kind of antidote, which implementation would benefit the sport.

Key-words: Culture, sports, advertising

Aceito em 05/09/2009 - Rev. Educ. Fís. 2009 - 26-31. Rio de Janeiro - RJ - Brasil

\section{INTRODUÇÃO}

Desde o nascimento de sua estrutura organizacional em junho de 1984, o Comitê Olímpico Internacional oferece uma gama de exemplos ligados à industria cultural. O ideal do Barão de Coubertin de reativar os Jogos Olímpicos, como uma forma de minimizar as tensões do mundo moderno, esbarrou no belicismo do homem vivente no século $X X$.

$\mathrm{Na}$ Grécia de Zeus as guerras experimentavam um processo de trégua sagrada para que os Jogos Olímpicos se consumassem. Nesta nova fase ocorre exatamente o contrário: as Olimpíadas são canceladas para que as guerras tenham sua normal continuidade. Em 1916, 1940 e 1944, os Jogos marcados para Berlim, Tóquio e Londres, respectivamente, foram suspensos devido a dois conflitos internacionais de enormes proporções: a primeira e a segunda grande guerra.

Se este fato pode ser ironicamente consignado como um novo iluminismo, representado por interesses de dominação se sobrepondo à prática sadia do esporte, uma outra situação é ainda mais flagrante, segundo os postulados de Rouanet (1) ideais de Coubertin eram puramente amadores ao criar os Jogos Olímpicos; hodiernamente, os patrocínios representam a alma de toda a estrutura organizacional da competição.

O esporte como veículo da indústria cultural se transforma em mercadoria. Surge, então, a publicidade com o marketing e o merchandising atuando como elementos de ponta, significando um novo iluminismo revestido de interesses mais espúrios.

Wilson (2) destaca que «Marx nos apresenta a imagem de um mundo em que as mercadorias mandam nos seres humanos», $\mathrm{E}$, realmente, hoje, a comercialização 
do esporte acaba ditando a forma de procedimento do homem.

\section{Conceituações Sobre Esporte}

Alguns "filósofos" da Educação Física Brasileira tentam estabelecer uma diferença entre desporto e esporte. Para eles, esporte é a prática da atividade física sem maiores comprometimentos com a competição ou com regras pré-estabelecidas, enquanto desporto corresponde à disputa em busca de pontos, representando, em última instância, a luta por vantagens pecuniárias diretas ou indiretas.

Tal teoria não passa de um sofisma. Esporte e desporto tem idêntico significado. $\mathrm{Na}$ filologia de Aurélio Buarque de Holanda (3), o vocábulo desporto referencia esporte como a palavra exata, conceituando-a como o conjunto dos exercícios físicos praticados com métodos, individualmente ou em equipes.

A criação do Conselho Nacional de Desportos (CND), em 1941, durante a vigência da ditadura - Vargas, praticamente institucionalizou o vocábulo desporto, conceituado, então, como atividade física com finalidade competitiva (e recreativa), que toma a forma de uma luta de seu executante consigo mesmo ou de uma competição com outros exercitada na conformidade de regras pré-estabelecidas.

Coubertin definiu o esporte como o culto voluntário e habitual do esforço muscular intensivo, apoiado no desejo de progresso e podendo ir até o risco. Souchon e May ${ }^{(4)}$ foram bem mais concisos ao conceituarem o esporte como luta e um jogo. Diz-se, também, que o esporte é a prática metódica de exercícios físicos, que consistem geralmente em jogos competitivos, entre pessoas ou grupos de pessoas, organizados em partidos. É outra definição dicionarizada.

Fanali ${ }^{(5)}$ define esporte como o conjunto de atividades especificas de emulação, na qual se valorizam, intensamente, as formas de praticar os exercícios físicos, para que o indivíduo ou grupo cheguem ao aperfeiçoamento das possibilidades morfofisiológicas e psíquicas, concretizando em recorde ou em superação de si mesmo ou da concorrente. Trata-se de uma conceituação científica, cuja compreensão exige de quem a lê conhecimento suficiente para interpretá-la.

Assemelhando-se à definição do CND, que nela se baseou embora os indivíduos que à época dirigiam o órgão estatal do esporte brasileiro o neguem - o Conseil Internationale d' Education Physique et Sport (CIEPS) ${ }^{(6)}$ divulgou em 1964, por inspiração de seu presidente - o inglês Philip Noel Baker, ganhador do Prêmio Nobel da Paz em 1939 - o "Manifesto Mundial do Desporto", que no preâmbulo define o esporte como «toda atividade física, sem caráter de jogo, que toma forma de uma luta de seu executante consigo mesmo, ou de uma competição com outros», destacando que "se essa atividade se opõe a outrem, deve sempre praticar-se com espírito leal e cavalheiresco».

Tubino (7) define o esporte como um fenômeno sociocultural cuja prática é considerada direito de todos e que tem no jogo seu vínculo cultural e na competição seu elemento essencial, o qual deve contribuir para a formação e aproximação dos seres humanos ao reforçar o desenvolvimento de valores como a moral, a ética, a solidariedade, a fraternidade e a cooperação, o que pode torná-lo um dos meios mais eficazes para a convivência humana.

Situando o esporte como um jogo concreto por excelência, Mahen ${ }^{(8)}$ ex-diretor da UNESCO, conceitua-o como um Jogo que expressa emoções líricas ou emoções dramáticas e, às vezes, também trágicas; é um jogo extraordinariamente sério.

\section{Considerações Sobre Indústria Cultural}

A exemplo do esporte torna-se necessário tecer algumas considerações sobre indústria cultural, para que possamos estabelecer um elo entre as duas manifestações e realmente definir a influência da indústria cultural sobre o esporte.

Theodor Adorno, cognominado o «pai da indústria cultural», situa a cultura fornecida pelos meios de comunicação de massa a indústria cultural, como se orientando 
não pelo seu conteúdo, mas segundo o princípio de sua comercialização e lucro, Ela fabrica produtos adaptados ao consumo de massa, os quais determinam e garantem este mesmo consumo. Seu efeito é o de antidesmistificação; ela se constitui num meio de tolher a consciência do indivíduo, de impedir a formação de pessoas autônomas e livres.

Segundo Adorno e Horkeimer ${ }^{(9)}$, podemos considerar suspeita a atitude de levar a sério a indústria cultural, mas querer subestimar sua influência seria uma prova de ingenuidade. Ela deve ser vista com seriedade, porém, de modo crítico, não se curvando diante do monopólio da transmissão de valores e padrões conformistas. Os intelectuais ironizam tal cultura, mas nada fazem; acomodam-se a este fenômeno, tentando conciliar suas reservas à indústria cultural com o respeito diante do poder, o qual reflete seu sentimento de impotência.

A importância de Adorno consiste no fato de que, partindo da análise do que constitui a indústria cultural e alertando-nos para que a encaremos de modo sério e crítico, aponta conseqüências negativas de tal movimento para a consciência e liberdade do homem, na medida em que este não é seu sujeito, mas seu objeto. Por outro lado, protesta contra a crítica não-ativa e a acomodação dos intelectuais.

Adorno não só acusa as influências negativas dos meios de comunicação de massa, como também aponta a possibilidade do homem atuar sobre elas. Mas, perguntase: o que é a indústria cultural? Ela pode ser definida como um complexo de produção de bens culturais, disseminados através dos meios de comunicação de massa, que impõem formas universalizantes de comportamento e consumo. É a comunicação de massa funcionando como sistema mercantil e industrial. É a própria indústria cultural que impõe a cultura de massa.

Mendonça ${ }^{(10)}$ considera a indústria cultural - referenciada primeiramente por Adorno em 1947 no livro Dialektik der Aufklãrung, escrito em parceria com Horkheimere, publicado em Amsterdam - como pedagógica, de fundo social, em que o efeito psicológico é o grande beneficiado, representando o estudo da comunicação sob o enfoque dos efeitos sociais de caráter ideológico dos meios de comunicação, efeitos esses que subordinam a ideologia ao princípio de comercialização da informação. O mesmo autor afirma que «a categoria de indústria cultural veio transformar a compreensão fenomenológica da chamada comunicação de massa, menos por ser pedagógica e mais por principalizar os efeitos ideológicos da mídia na referida compreensão» .

Horkheimer e Adorno (9) dedicaram um capítulo à Kulturindustrie, onde analisaram detalhadamente o choque do desenvolvimento cultural e tecnológico em que a imitação surge como um valor absoluto.

Ao escolher a expressão «indústria cultural» em substituiçãoa "cultura de massa», Adorno objetivou excluir a interpretação dos que pretendem que a cultura nasceu expontaneamente nas massas, como forma contemporânea de arte popular.

As massas não são a medida, mas a ideologia da indústria cultural. Indústria é entendida no sentido de estandartização e racionalização das técnicas de distribuição e não tanto do processo de produção. Mantémse a serviço de terceiros. E o comércio? Quanto mais desumanizada sua ação e seu conteúdo, a propaganda é mais ativa e bem medida.

A ideologia e o espírito da indústria cultural são glorificados como fatores de ordem. Quando alega seu desinteresse em ser arte, a indústria cultural representa a ideologia que se exime da responsabilidade do negócio de que vive.

A indústria cultural tem sofrido críticas constantes, entre elas as proferidas por Merquior e Umberto Eco. Este, segundo Mendonça ${ }^{(10)}$, dá a entender que "a concepção analítica de indústria cultural descreve a ação dos meios de comunicação de modo a levar os receptores do ponto de vista político a um beco sem saída».

Apesar de se revelar um nostálgico da arte iluminista, por se tratar de um apologista da indústria cultural, Adorno pode 
ser responsabilizado como o "coveiro» do iluminismo, uma vez que a indústria cultural trouxe o fim desse movimento.

\section{Relações Entre Cultura e Esporte}

Segundo Maheu ${ }^{(8)}$, o esporte é uma cultura e no estado de coisas atual realiza a função de cultura para massas imensas. O esporte é um fenômeno paralelo ao fenômeno cultural. Esporte e cultura procedem da mesma fonte, o lazer. Não há cultura e nem há esporte sem lazer, sem esse tempo e essa energia disponível que o trabalho deixa ao homem e com os quais pode fazer o que quiser.

No momento atual, o esporte é talvez a forma de lazer mais difundida. Em muitos países ele é o lazer por excelência e, se não se conjuga com a cultura, pelo menos está destinado a fazer-lhe concorrência. Porque, se o esporte e a cultura extraem do descanso uma origem comum, não há outro remédio senão reconhecer que ele exerce nas massas atração muito mais forte que a cultura.

Entre as diferentes atividades que ocupam, há uma comum ao mesmo tempo ao esporte e à cultura, que se chama jogo, o qual introduz um elemento especial, a espontaneidade. É uma atividade livre e desinteressada de homens livres que encontra em si mesmo seu próprio valor, sua própria recompensa, sua própria justificação. Outro tanto ocorre com a cultura, que é jogo e ficção, em relação às atividades austeras da vida; inclusive o pensamento filosófico ou o pensamento de livre cultura é uma atividade lúdica e o esporte também essencialmente um jogo. Não é por casualidade que em inglês, por exemplo, se utiliza da mesma palavra para designar jogo e esporte. Em ambos os casos encontramo-nos com uma atividade desinteressada e espontânea.

Assim como no teatro, o público participa do drama que se desenvolve diante dele, de forma que somos ao mesmo tempo atores e espectadores, assim também no estádio, produz-se entre o público e os atletas um extraordinário movimento de participação. A vista de quão estreitos são o paralelismo e a comparação entre um espetáculo cultural como o teatro e o esporte, diríamos inclusive que o espetáculo esportivo é o verdadeiro teatro moderno. No estádio ou no público, o espectador se cala, se recolhe, quando - atleta se prepara, se concentra, antes de executar um salto em altura ou quando Romeu faz juras de amor à sua Julieta.

O esporte, como o teatro, a literatura e a arte, é um criador de mitos. Há uma mitologia esportiva cujas manifestações podem talvez parecer bastante ridículas aos intelectuais. Tem suas lendas, seus heróis e, seja qual for sua maneira de expressar-se, atesta um poder de criação que revela o estreito parentesco entre as artes completas e o esporte.

Também torna-se desnecessário afirmar que o esporte é criador de beleza. Através do gesto ou do ritmo, que representam a conquista do espaço e do tempo, o esporte se aproxima das artes criadoras de beleza. Nenhum atleta pode realizar uma façanha, sem um domínio tão perfeito do corpo através do tempo e do espaço, de maneira que não haja diferença entre os gestos que executa e o ritmo no qual se integram como os mais belos espetáculos de dança, as mais belas cadências da linguagem, os mais belos ritmos arquitetônicos e esculturais, ou os mais belos jogos de cores e de luz. Portanto, na arte ou no esporte encontra-se, nos que a eles se entregam, essa mesma afirmação da personalidade inimitável que se chama estilo.

Pode haver vários atletas que percorram a mesma distância no mesmo tempo recorde, mas não há os que o façam da mesma maneira. Dois, três atletas podem saltar a mesma altura ou lançar à mesma distância, mas cada qual à sua maneira e conforme sua personalidade. Assim se afirma o indivíduo. Até na perfeição, parece melhor alcançada, a que caracteriza ao mesmo tempo a arte e o esporte.

Indústria Cultural e Esporte

O relacionamento entre cultura e esporte por nós abordado linhas cima, serve de base para que se demonstre a influência exercida pela indústria cultural sobre o esporte.

Adorno (9) afirma que "a indústria cultural se desenvolveu com a primazia dos efeitos 
do exploit tangível do particular técnico sobre a obra, que outrora trazia a idéia e que foi liquidada". O particular, ao emancipar-se, tornara-se rebelde, e se erigira, desde o romantismo até o expressionismo, como expressão autônoma, da revolta contra a organização. O simples efeito harmônico tinha cancelado na música, a consciência da totalidade formal; a cor particular na pintura, a composição do quadro; a penetração psicológica, a arquitetura do romance. A isto põe fim a indústria cultural. Só reconhecendo os efeitos, ela despedaça a sua insubordinação e os sujeita à fórmula que tomou o posto da obra. Molda da mesma maneira o todo e as partes. Privados de oposições e conexões, o todo e os pormenores têm os mesmos traços.

No esporte, a indústria cultural tem se feito sentir através da supremacia de um profissionalismo avassalador, que se sobrepõe ao "fair-play" da disputa, à beleza do gesto na prática do lançamento de um dardo ou na execução de um drible no futebol. Só importa o efeito da vitória, porque nos bastidores de tudo está a influência do marketing e da publicidade, está a comercialização. Neste particular, a vitória obtida por meios lícitos e belos, com dribles encantadores e gols maravilhosos, tem o mesmo efeito do triunfo alcançado graças a um erro involuntário (ou não!) do árbitro.

Os produtos da indústria cultural podem estar certos de serem jovialmente consumidos, mesmo em estado de distração: o artigo anunciado na camisa de um jogador de voleibol ou na fita que envolve a cabeça de um tenista representam uma estratégia de marketing e de publicidade. São produtos da indústria cultural em condições de serem consumidos, principalmente por todos aqueles que acompanham a performance do voleibolista ou do tenista.

Adorno e Horkeimer (9) afirmam em "O lluminismo como mistificação de massas", que os cineastas consideram com suspeita todo manuscrito atrás do qual não encontram um tranquilizante "best seller". Da mesma forma, no esporte se faz um investimento na aquisição do passe de um jogador de futebol, se ele, sendo desconhecido para o clube que o cobiça, vem bem recomendado; só se faz um investimento de patrocínio se o atleta já é consagrado ou está em vias de consagração. Novamente a comercialização do esporte impera e a indústria cultural está presente através da veiculação da publicidade.

A indústria cultural perpetua a indústria do divertimento. Eai está outra influência flagrante sobre o esporte, o filão mais rentável para carrear recursos à indústria do divertimento, principalmente segundo o novo iluminismo representado pelo profissionalismo que invadiu a prática da maioria das modalidades esportivas, eliminando a singeleza e a pureza que o amadorismo lhes impregnava.

Adorno e Horkheimer (9) consideram "pelo menos duvidoso que a indústria cultural preencha mesmo a tarefa de diversão de que abertamente se vangloria. E outra vez o esporte se encaixa nesta teoria: presentemente, a disputa de uma competição de futebol ao invés de às vezes divertir aqueles que a assistem, causa-lhes irritação e enfado, tal a apatia dos que a protagonizam, receosos de perderem as vantagens que Ihes foram concedidas através de mensagens publicitárias que ostentam em seus uniformes, caso sejam derrotados. As duas equipes jogam pelo empate, que ao menos garante a sobrevivência do marketing para ambas até uma próxima partida. Aí cabe também destacar que a indústria cultural continuamente priva seus consumidores do que continuamente lhes promete.

A mistificação está no fato de que a indústria cultural estraga o prazer, manipulando as distrações e permanecendo voluntariamente ligada aos clichês ideológicos da cultura em vias de liquidação. E o esporte já sofre essa influência, quando se rende a postulados profissionais, que não só inflacionam o mercado como se ligam a lugares comuns e chavões que fatalmente provocarão, em futuro próximo, uma revolução irreversível: a profissionalização dos Jogos Olímpicos, o que certamente aniquilaria moral e fisicamente o Barão de Coubertin, caso estivesse vivo.

A indústria cultural tem a tendência de se converter em um conjunto de protocolos e, por esta mesma razão, de se tornar o irrefutável profeta do existente, segundo 
Adorno e Horkheimer (9). Neste caso, a influência transmite-se através de uma prática burocrática do esporte na qual o atleta faz apenas o necessário para vencer. Não Ihe interessa se tornar um goleador ou superar um recorde.

Os filósofos acima citados sustentam que «quanto mais sólidas se tornam as posições da indústria cultural, tanto mais brutalmente esta pode agir sobre as necessidades dos consumidores, produzi-las, guiá-las e discipliná-las, retirar-lhes até o divertimento». Esta ação tende a influenciar a prática da atividade desportiva, tornando-a um ato mecânico, o que já vem ocorrendo, embora alguns heróicos praticantes ainda estejam integrados à era do romantismo, jogando, nadando ou correndo como autênticos idealistas, procurando oferecer o esporteespetáculo, sem se preocupar em cumprir tão somente uma obrigação.

Ao produzirem «O Iluminismo como Mistificação de Massas», Adorno e Horkheimer (9) afirmaram também a possibilidade evidente de se viver sem a indústria cultural, considerando a saciedade e a apatia que ela gera entre os consumidores. Os dois filósofos alemães opinaram que, por si mesma, a indústria cultural pode bem pouco contra este perigo. Para eles, a publicidade representa o elixir para a sobrevivência da indústria cultural.

No "esporte também a publicidade é a poção mágica que o mantém permanentemente com vida" Nos países capitalistas esta é uma verdade irreversível e naqueles que adotam o socialismo moscovita ou outros regimes semelhantes, o Estado se encarrega de veicular o marketing. De qualquer maneira, a indústria cultural sempre está presente.

\section{CONCLUSÕES}

Com base nas considerações feitas ao longo deste trabalho, estabelecemos como conclusões:

A bela e leal prática do esporte tem seus dias contados, devido à crescente e irreversível influência da Indústria Cultural;

A sêde de comercialização da Indústria
Cultural, objetivando a implantação do marketing e do merchandising, exige uma simplificação de métodos de trabalho, despertando inclusive o recurso do uso da violência em busca de um resultado almejado por todos - a vitória;

Para que o objetivo final, representado pelo êxito, seja atingido, a Indústria Cultural deve colocar ao alcance do esporte todos os modernos recursos de uma de suas mais eficientes vertentes: a publicidade.

\section{REFERÊNCIAS BIBLIOGRÁFICAS}

1. Rouanet SP. As Razões do lluminismo . São Paulo: Companhia das Letras, 1987.

2. Wilson E. Rumo à Estação Finlândia. São Paulo: Companhia da Letras, 1987.

3. Holanda AB. Novo Dicionário da Língua Portuguesa. $2^{\mathrm{a}}$ ed. Rio de Janeiro: Nova Fronteira, 1986.

4. Souchon P \& May J. In: Gillet Bd. História Breve do Desporto. Lisboa: Editorial Verbo, 1961.

5. Fanali OAAC. Terminologia da Educação Física e Desporto. Brasília: SEED/MEC, 1978.

6. Manifesto Mundial do Desporto, CIEPS, 1964. Homo Sportivus. Rio de Janeiro: Palestra Edições Desportivas 1985.

7. Tubino MJG, Garrido F, Tubino FM. Dicionário Enciclopédico Tubino do Esporte. Rio de Janeiro: SENAC Editoras, 2007.

8. Maheu R. Desporto e Cultura. Homo Sportivus. Rio de Janeiro: Palestra Edições Desportivas 1985.

9. Horkheimer M, Adorno TW. A Indústria Cultural. O iluminismo como Mistificação de Massa. In: Teoria da Cultura de Massa, Rio de Janeiro: Paz e Terra, 1978.

10. Mendonça ASL. Indústria e Cultura, Rio de Janeiro: ECO/UFRJ, 1987.

11. Merquior JG. O Marxismo Ocidental. Rio de Janeiro: Nova Fronteira, 1986.

Endereço para correspondência:

Av João Luiz Alves, s/nº (Forte São João) - Urca

Rio de Janeiro - RJ - Brasil - CEP 22291-090

e-mail: jmcapinussu@hotmail.com 